\title{
Sizing up the Antistrophos View of Pragmatics-Rhetoric
}

\section{Relationship}

\author{
Guojin Hou ${ }^{1 *}$ \\ ${ }^{1}$ Institute of Foreign Linguistics \& Applied Linguistics, Huaqiao University, Quanzhou, China \\ * Guojin Hou, E-mail: nationelf@ 126.com
}

Received: October 12, 2017 Accepted: October 17, 2017 Online Published: October 31, 2017

doi:10.22158/selt.v5n4p641 URL: http://dx.doi.org/10.22158/selt.v5n4p641

\begin{abstract}
This paper is an introduction to and comment on Liu \& Zhu's antistrophos view of pragmatics-rhetoric relationship. It unfolds why they choose "antistrophos" rather than "counterpart(s)" for the bilateral positing, holding that "counterpart" is not impossible for that end. Then the paper affirms the merit of their "antistrophos view", capable of facilitating "reciprocal and reversible transformation" of pragmatics and rhetoric. In terms of the bilateral relations, this paper maintains the stance of radical pragmaticism of the complementarity camp. Finally we discuss the possibility of the disciplinary integration resulting in pragma-rhetoric.
\end{abstract}

\section{Keywords}

pragmatics, rhetoric, antistrophos, interdisciplinarity, integration, pragma-rhetoric

\section{Introduction}

What is the relationship between pragmatics and rhetoric? If $\mathrm{P}$ is the study of how utterances get their meanings in actual contexts, and $\mathrm{R}$ is the study of how human beings use signs for communication, we can easily see the similarity between P and R, but they respectively represent two different disciplines, pragmatics and rhetoric, because we take the defining ideas of Leech (1983, p. x) and Chen (2010, p. 32) for the above $P$ and $R$ respectively.

Liu \& Zhu's (2011) antistrophos view of pragmatics-rhetoric relationship provides an interesting perspective for the two disciplines cooperating in a certain way so that each is responsible for a certain pragmatic labour (task). I attempt to size up their Antistrophos view of pragmatics-rhetoric relationship, while addressing the possibility of the disciplinary integration resulting in pragma-rhetoric.

\section{Literature Review}

The earliest discussions of the pragmatics-rhetoric relationship were found in Qi (1983, 1986), followed by Chen (1985), Dasenbrock (1987), Yuan (1987), Chi (1989), Sperber and Wilson (1990), 
Verschueren (1995), Dascal and Gross (1999), He (2000), Zhang (2000), Wang and Chen (2005), Liu (2003), Ilie (2003), Liu (2004), Hopper (2007), Zong and Liu (2007), and so on and so forth. Each of these authors has his/her own linguistic point of departure, methods and insights, creating a repertoire of numerous yet incongruous understandings about pragmatics and rhetoric and their bilateral relationship. There is, as we see, the distinction between a) the difference view (e.g., Yuan, 1987; Zong \& Liu, 2007), b) the borrowing view (e.g., He, 2000), c) the subordination view (e.g., Chi, 1989), d) the coordination view (e.g., Zhang, 2000), e) the convergence view (e.g., Hu, 2003), and f) the marriage view (e.g., Leech, 1983; Sperber \& Wilson, 1990; Dascal \& Gross, 1999; Li, 2002), and so on. Or there is the sharp contrast between a-c)'s divergence bias and d-f)'s convergence bias: The first three views are biased towards pragmatics-rhetoric differences, so that their views are that the two disciplines are so different from each other that they should borrow ideas from one another or A is subordinate to B or vice versa. The common thrust of the last three views is that the two subjects share so many similarities that they can hang together or join hands in theoretical constructions and formulations, on the border of marrying A to B for one new "family". For the time being, the convergence bias in d-f) outwits the divergence view overwhelmingly (see Zhang, 2015, p. 3).

In their recent paper "Rhetoric as the Antistrophos of pragmatics: Toward a "Competition of Cooperation' in the study of language use", Liu \& Zhu (2011, "L\&Z" for short hereinafter) forward their Antistrophos View ("AV" for short hereinafter) of pragma-rhetoric relations, and Non-Cooperative Principle (NCP, for short - a contrastive parody/analogy of Grice's CP). Their formulation is revealing and helpful to the meta-disciplinary construction of pragmatics and rhetoric, especially to the removal of some important misunderstandings concerning the two subjects and their mutual relationship. This current research notices some drawbacks of L\&Z's formulation and explores the possibility of remedying if not perfecting their $\mathrm{AV}$ (Note 1).

L\&Z (p. 3412) maintain that among other things, the relationship between pragmatics and rhetoric is far "more sophisticated and subtler" than generally taken for granted, for their similarity forces people to make a simplistic parallel comparison, which they say is certainly out of place. The two disciplines cannot be combined easily for "mutual appropriation" or "integration". On the other hand, they contend, a comparison of L\&Z's NCP and Grice's CP will enable us to understand their "common telos" and "problematics", their numerous "strategic points of contact", and more significantly their "ambivalent tendency". Apparently there is divergence and also convergence between pragmatics and rhetoric. Such being the case, it is unwise to consider the two disciplines as unrelated ones. But what relationship lies between them?

\section{L\&Z's Antistrophos View}

\subsection{Antistrophos or Counterpart?}

A little understanding of the complication of the relationship between pragmatics and rhetoric is far from enough, so L\&Z hold that a more useful interpretation or model is necessary for the circle of 
pragmatics and that of rhetoric to understand their "antistrophos relationship". In looking for their common goals and interests, L\&Z say, we can coordinate all attempts in all relevant research. Their term "antistrophos" derives from their imitation or analogy of classical or ancient art of dialectic vs. classical or ancient rhetoric. In Aristotle's model, rhetoric is interpreted as an "antistrophos of dialectic" (Note 2). The Greek term "antistrophos", according to L\&Z, is quite different from (unequal or unequivalent to), though often translated into, English as "counterpart" (p. 3413). The English word "counterpart", they claim, can mean any homologous, opposite or corresponding element or factor, encompassing (ibid.):

1) $\mathrm{X}$ is $\mathrm{Y}$ 's mirror-image;

2) $\mathrm{X}$ is Y's proportional opposite;

3) $\mathrm{X}$ is Y's exact parallel;

4) $X$ is equal to $Y$ in a certain or the same context;

5) $\mathrm{X}$ and $\mathrm{Y}$ hold in contrast like the Chinese yin and yang (of Taoism), making equally important halves of the entire one entity.

All in all, L\&Z say, "counterpart" is capable of expressing a small part of the meaning of "antistrophos" (p. 3413). Due to their opposition to a simplistic view of interdisciplinary relationship, they opt out "counterpart" while adopting the seemingly more difficult and complex term "antistrophos". If, according to L\&Z, pragmatics and rhetoric embrace each other as disciplinary "antistrophos", we can use such phrases for description as "mirror-image", "proportional opposite", "parallel", "analogue", "complement", among others, and make both disciplines as "inspiration for 'reciprocal' disciplinary reinvention" (ibid.). They say that this multi-faceted pragmatics-rhetorical configuration has three advantages over prior ideas: it can coordinate previous incongruous conceptions about the pragmatics-rhetoric relationship, so we can free ourselves from the simplistic view of it and no more regard pragmatics only as a Speech Act Theory (SAT) or Principle of Least Effort (PLE), nor look on rhetoric as no more than studies of "symbolic action(s)", viz., we save ourselves from taking the erroneous "prima facie analogy". On the contrary, the AV-based perspective allows for a more thorough investigation of the samenesses and differences between the two subjects (ibid.).

\subsection{What AV Can Do}

According to L\&Z, AV can make us realise that the "pragmatic effect" of utterances on the audience which pragmatics is concerned about, and the "rhetorical effect" of language expressions on hearer/reader which rhetoric is concerned about actually stand in "a mirror image-like parallel" (p. 3413). AV also helps us override the simple terminological comparison of "intention", "meaning", and "effect" of the two disciplines in our search for what really underlies the "circuits of signification" in actual communication. We know that in pragmatics intention and meaning can be accounted for by each other, so to speak, so that they are an indispensable, inseparable component for each other. In pragmatics, it is widely recognised that meaning is realised by the effect retrieved via (re)cognition of speaker/writer's intention, whereas in rhetoric it is known that intention is pinned down by a retrievable 
effect, i.e., rhetoricians equate meaning to the realisation of the persuasion intention, or in Burke's (1950/1969, p. 172) words, "Wherever there is persuasion, there is rhetoric. And wherever there is 'meaning', there is 'persuasion"' (Note 3).

Moreover, L\&Z (p. 3414) maintain that AV is able to facilitate pragmatics' and rhetoric's mutual "transformation" which is "reciprocal and reversible", valued by both disciplines, as it were, as "ultimate telos" as far as the bilateral relationship is concerned, and as "inspiration for 'reciprocal' disciplinary reinvention" (p. 3413). Pragmaticians, for instance, will feel it necessary to go beyond "maximally effective exchange(s) of information" for its narrowness. To be able to account for the general purpose that governs or guides other people's behaviours (Grice, 1989, p. 28), pragmaticians need rhetoric as an important pivot for theoretical formulation. On the other hand, rhetoricians worry about the thinness of "inherited lexicon", which is not capable of explaining all human cultural exchanges. A "dissipatory approach" will lead to the substitution of a good "method" by an "attitude (of humanistic contemplation)" (Burke, 1945/1969, p. 319). Rhetoricians can benefit greatly from pragmatics and, by means of clearer categories, rules and procedures, conduct a detailed, scientific, informed structural or formal (rhetorical) analysis (Leith, 1994, p. 225). That is why L\&Z (p. 3414) forward their NCP (also see Hou, forthcoming, b)), which, they say, can also enhance the "mutual transformation".

As noted above, AV makes pragmatics and rhetoric hug each other as a disciplinary "antistrophos", which as a theoretical stance can prevent people from taking a bilateral relationship of nothing but "reciprocal and reversible appropriation" and "reciprocal and reversible transformation", viz., AV disallows pragmatics to "swallow" rhetoric, or vice versa. It is perhaps worthwhile noticing Hopper's (2007, p. 236) view of "synecdochic perception" which suggests that rhetoric is "a form of pragmatics" on the one hand and that pragmatics and other disciplines are only the "micro end of rhetoric" on the other. L\&Z (p. 3414) do not agree with this view, or with the two-in-one view of A swallowing B or B swallowing A, viz., the gobbling/integration view, like Dasenbrock's (1987) "Austinian rhetoric", Dascal \& Gross's (1999) "Gricean/cognitive rhetoric". L\&Z say that the notion of "antistrophos" and $\mathrm{AV}$ can remove the obstacle or tension between pragmatics and rhetoric and make them "independent fields" sharing a "common pursuit". That is to say, by AV, a brand-new pragmatics-rhetoric relationship is founded, where we envisage "competition of cooperation" with the feature of “cooperation of competition" (in Burke's (1945/1969, p. 403) terms).

In short, interdisciplinary relationship is in nature a dynamic, constructive enterprise, and a good, plausible bilateral relationship enables the relevant disciplines to develop well and fast. In other words, how to maintain such a bilateral relationship determines whether the relevant disciplines go forward or backward (L\&Z, p. 3414). Their option of the classical term "antistrophos" as a means, model or perspective for retrospection of the pragmatics-rhetoric relationship can be explained by their belief in the hand-in-hand improvement of pragmaticians' and rhetoricians' interpretation of the disciplinary nature of the two subjects for a new academic horizon (ibid.). 


\section{Comments upon AV}

\subsection{Distance between Pragmatics and Rhetoric}

Discussion of interdisciplinary ties usually involves the origination of names of the disciplines in question and historical metamorphosis. And in terms of the relationship between pragmatics and rhetoric, it is advisable to cash in on the views on the relationship between pragmatics, semantics, and syntax.

"Pragmatics" as an academic name for a discipline was coined by Charles W. Morris in the 1930s, constituting one third of semiotics (the Morrisian trichotomy), the other two being syntactics (much the same as today's "syntax" and semantics) — a trilogy or triad, each responsible for accounting for one of the relationships between reality or real world entities, symbols or words, and interpreters or users. Namely, language studies of modern times are composed of three core or pillar branches: pragmatics, semantics, and syntax. If syntax deals with the relationship between words or linguistics symbols, semantics copes with that between these linguistic elements and the people and objects in the three "worlds": physical, social, and mental world, then pragmatics shoulders the task of explanation of the tie between these language forms and the communicators that use them in a context. From a particular point of view, the former two disciplines touch upon the language as a system, or the linguistic components that form a system, i.e., Saussure "langue". It is pragmatics that is concerned about the daily uses and usages of language expressions, i.e., language used live or online in daily written and oral communication, especially the latter, including fragments, one-member sentences, elliptical sentences, riddles, idioms, brain-twisters, tongue-twisters, communicators' idiolect, and so on, orienting towards Saussure's "parole".

In the history of traditional linguistic research of syntax and semantics, anything that had to do with such parametres as users, pragmatic distance, intention, presupposition, implicature, deixis, context, inference, to name but a few, most probably found its way in the "wastebasket" of the researchers in question. However, interestingly enough, most if not all of the dust or dirt in the "wastebasket" turned out in due course to be what makes now classical topics of research for pragmatics. We know that various pragmaticians' interpretations of these topics and issues and problems are very good, better than nothing at least, better than those of the 1970s and 1980s when pragmatics was just born, and nowadays better and better, but new times call for greater plausibility of explanations. With modern developments of pragmatics, we are finding more room for improvement of the discipline proper, borrowing heavily from adjacent disciplines, hence interface pragmatics studies on their way. Any of the above-mentioned pragmatic parametres or topics can last a life time for any pragmatics researcher. Owing to the tripartite "labour division" of the three sister disciplines, no one of them dares to claim an ambition to devour any other discipline. Take Chomsky's Generative Grammar (GG) for example, he seldom, if ever (e.g., in diagrams of representations of language), mentions semantics or "semantic representation", viz., GG is meaning-free or meaning-proof study of language. This is of course not to blame him, but to suggest that among other things, each discipline or sub-discipline, or any subject or 
topic under the pen of a certain researcher, is subject to its or his/her own academic goal and responsibilities and cannot hope to be a master or Jack of all trades. Likewise, semantics in the literature of John Lyons (2000) and John Saeed (2012) focuses on static meaning, namely, the meaning of words, phrases, and sentences that helps make a semantic system, hence systematic meaning. In their study of such default or decontextualised meaning, semanticians largely ignore polysemanticity, let alone multifunctionality. It is true that occasionally we can lay our hand on some semantic literature mentioning or discussing succinctly such pragmatic topics as implicature, context, inference, pragmatic/speech act (Jacob Mey's "pract"), but it tends to be brief, unreflecting, and simplistic. To pragmatics per se, these pragmatics-specific issues naturally fall within the reach of average pragmatic researchers. And they may spare some space for syntactic or semantic concerns, making them the basis for further dynamic or interactive semantic studies, otherwise their survey seems "empty". How can pragmatics hope not to be "empty" without any semantic or syntactic involvement, and how can semantics or syntax hope not to be "blind" without pragmatic guidance? (Huang, 2001, p. 9) (Note 4). Interdisciplinary integration does occur from time to time - the integration of syntax and pragmatics results in syntactico-pragmatics, while the integration of semantics and pragmatics sees the birth of semantico-pragmatics. Syntactico-pragmatics, if it works at all, does not mean the taken-for-granted addition or composition of the two disciplines involved; rather it allows for an interdisciplinary perspective on syntactic or pragmatic issues, at least a pragmatic view of syntax, as seen in Huang's (1994) syntax-pragmatics of the Chinese anaphora, especially its long-distance anaphora, or He \& Chen's (2004) attempts in pragmatic usages of English syntax. By the same token, semantico-pragmatics, rather than putting the two component subjects together, indicates another interdisciplinary perspective on meaning problems. Hou (2013) is a study of the "labour division" of semantics and pragmatics in terms of meaning investigation. All in all, the three classical linguistic inquiries as discussed above, have formed a widely-accepted relationship of mutual association, mutual benefit, and inter-complementarity. The so-called "integration" or the post-integration interface linguistic inquiry, whatever its name or its focus, can add to the catalogue of interfaces, while serving the development of each relevant discipline per se.

Then, let us return to the relationship between pragmatics and rhetoric.

The term "rhetoric" can be dated back to Plato's Gorgias (350 BC), which first referred to "art of public speaking" exclusively or the "art of persuasion" (Larsson, 1998, p. 1). Rhetoric found itself fully expounded in Aristotle's On Rhetoric, approaching a science or discipline. Platonian or Aristotlean rhetoric's counterpart in China is 文心雕龙/Wen Xin Diao Long (The Literary Mind and the Carving of Dragons (Note 5)) and Chen's (1932/2008) early works on rhetoric in the 1930s, till neo-rhetoric or modern rhetoric of rhetoricians like Burke (1945/1969).

Modern rhetoric is largely concerned about active and passive rhetoric. "Active rhetoric" addresses rhetorical means or devices like simile and metaphor, which are meant to achieve the greatest possible "rhetorical effects" for a sentence or text, just as pragmatic strategies and means (as far as pragmatics is 
concerned) help communicators achieve the greatest possible "pragmatic effects" for an utterance in a certain context. By "passive rhetoric" is meant various ways of expressing ideas and thoughts, including phonological/sound styles, lexical/diction styles, syntactic/sentence styles, textual/text styles, and so on, agreeing largely with a lot of syntactic and semantic concerns.

In the Middle Ages, rhetoric used to be one of the three major courses in school education: logic, grammar, and rhetoric. Rhetoric is also one third of linguistic studies: grammar, rhetoric, and poetics, according to Burke (1945). Some like Liu \& Zhu (2011, p. 3407) even hold rhetoric as a dominant discipline in charge of two thirds (the first two) of stylistics: pathos, ethos, and logos.

Different from classical rhetoric (of ancient Greek times) treating rhetoric as "art of persuasion" or sophistry, and traditional rhetoric (of the last two centuries) considering rhetoric as figurative means, modern rhetoric (of the last five decades) can be looked on as a study of active and passive rhetoric on the foundation of modern linguistics and other sciences (Chen, 2010, pp. 33-34). Like pragmatics, rhetoric gives birth to "children" like phono-rhetoric, lexico-rhetoric, grammar rhetoric, textual rhetoric, stylistic rhetoric, contextual rhetoric, cognitive rhetoric, and so on (Hou, forthcoming, a)).

In terms of semantics-pragmatics relationship, Hou (2013) criticises the point of view called "semanticism" which puts semantics before all other disciplines, and the viewpoint of "pragmaticism" that holds pragmatics prior to all others. We contend that the three disciplines do not constitute a relationship of superiority vs. inferiority or of "swallower" vs. "swallowee" and that instead they should treat each other as a mutually complementary tripling or a "tripod unity", hence interdisciplinary complementarism (see Brown et al., 2008, pp. 29-30). If this makes sense, we adhere to "radical pragmaticism" (see Huang, 2001), the stance that values pragmatics mildly prior to semantics, partly because of our pragmatic research in the past and the guidance role of pragmatics in the meta-disciplinary speculations. Likewise, in terms of the pragmatics-rhetoric relationship, we are opposed to the idea of "rhetoricism" which places pragmatics under or below rhetoric in importance, and the notion of "pragmaticism" that self-importantly puts pragmatics before all else. It should be noted that pragmatics, grammar, semantics and rhetoric each plays a different and important role. The claim of any one discipline's being better or higher than other disciplines cannot hold water. Nor is it plausible to have one "gobble up" any other discipline. The four cousin disciplines are independent yet inter-complementary. In case of interface studies, pragmatics plays the role of "theoretical guide" or "academic pace-setter", if pragmatics gets the floor at all.

\subsection{Is Mutual Appropriation Possible?}

No one can always expect to have a perfect picture of the relationship between any two disciplines because of the disciplinary and interdisciplinary complexity and the possibility or reality of interdisciplinarity or interface studies. There is also interdisciplinary borrowing, permeation, merge, (co-)reference and so on. Therefore people from various domains or even from the same domain may not agree completely with one another. The relationship between pragmatics and rhetoric is more than “more complicated and subtler" (as L\&Z (p. 3412) noted). Many pragmaticians, like Leech (1983), 
Sperber and Wilson (1990), Gu (1993, 1994), Verschueren (1995, 2000), Ilie (2001, 2003), and Abbott (2006), express their different views on this bilateral relationship, not equally plausible, or actually far from all correct. Most regard rhetoric or rhetorical devices as "instrumental discourse". Similarly, rhetoricians like Benjamin (1976), Beale (1978), Dasenbrock (1987), Bohman (1988), Jost and Olmsted (2004), Jarratt (2007), Zarefsky and Benacka (2007), Richards (2008), Lunsford et al. (2009), and Cassin and Goffey (2009), whether they are interested in pragmatics or not, bear some misunderstandings about it, for some of them narrow pragmatics down to the scope of Austin's or Grice's views (L\&Z, pp. 3404-3406).

We understand why $L \& Z$ (p. 3412) stand against a simplistic view of pragmatics-rhetoric amalgamation or parallelism but it is really difficult to understand or agree with their opinion of opposing pragmatics-rhetoric "(mutual) appropriation". Considering their "common interests and goals" and more importantly their differences, we argue that the two disciplines are able and ought to benefit from and make use of each other for better improvement and development. As noted in $\S 1$, they even share a big proportion of their respective definitions, in spite of the diversity of definitions of both pragmatics and rhetoric, because they share the keywords of "meaning" and "effect". Besides, the two subjects have ten similar meta-disciplinary predicaments or puzzles (e.g., in terms of meta-science, research domains, developmental orientations, and theoretical loaning). The similarities cannot deny or hide the differences between pragmatics and rhetoric, e.g., differences in what meaning and what effect in what context the two disciplines each should concern. In fact, what a pragmatician means by "meaning", "effect" and "context" may be quite different from what a rhetorician means by much the same words (Hou, forthcoming, a)). The convergence and divergence of the two kinds of inquiries make the mutual benefit and academic win-win possible.

\subsection{Isn't It a Terminological Play?}

L\&Z's AV comes from and is based on what they say is a more correct understanding of the relationship between pragmatics and rhetoric (at least more so than the ideas they call into question and criticise, as they hope) and their understanding and option of the Greek term "antistrophos" instead of its English counterpart "counterpart".

L\&Z mean to introduce to the linguistics circle a "more useful interpretation" or theoretical "model/framework", composed mainly of the CP-parody NOC and the pragmatics-rhetoric "antistrophos" relationship or AV (see Hou, forthcoming, b)). Here below we focus on the latter, i.e., AV.

It is worthwhile, as L\&Z claim, to seek the "common interests and goals" of the two disciplines which can hopefully "coordinate" all research attempts. In the recent literature of pragmatics and rhetoric it is not hard to discover "mutual appropriation", perhaps more rhetorical borrowing from pragmatics than the other way round. Input of 修辞学/xiucixue (rhetoric) as a keyword on the internet (CNKI, China's publication data) can result in 712 papers. Using 修辞学(see above) plus 语用学/yuyongxue (pragmatics) as keywords expects a discovery of 41 papers. Most of the papers that take advantage of 
such borrowing or appropriation are rhetorical papers that owe pragmatics a huge debt. Despite their similarities, these papers/researchers have no consensus regarding the pragmatics-rhetoric ties. So a meta-disciplinary speculation or debate on the interdisciplinary relationship like L\&Z's is interesting and revealing to the two disciplines and relevant interface studies.

However, the reason why L\&Z happen to prefer Aristotle's term "antistrophos" to the common accessible term "counterpart" has not been and really cannot be fully accounted for in their paper, since as we see it, it is just a defamiliarisation or estrangement game of terms. The term "counterpart" can be equally applicable, or more so.

Now that indeed Aristotle said rhetoric is "antistrophos of dialectics" to the delight of $L \& Z$ who like this word better than "counterpart", we can translate the former into Chinese as 孪亲/luan qin (something like "twin"), to make it (more) different from "counterpart" or any other English synonym, in possible Chinese discussions. L\&Z accuse some people (possibly) of mistranslating "antistrophos" into English as "counterpart", because they hold the two words as total nonequivalents (p. 3413). They provide a lengthy explanation to what "counterpart" can mean and imply, but we still can hardly grasp their point of devaluating this term. "Counterpart", they say, usually has four or five meanings (§3.1): $\mathrm{X}$ is Y's "mirror-image", "proportional opposite", "exact parallel", and "equivalent". Just as any word bears more than one meaning or sememe, as explained by lexicographers, but a word used in a sentence in a certain context usually expects one and only one interpretation, to meet the relevance expectation of both interlocutors in actual communication, so, the polysemous "antistrophos" does not guarantee the polysemy of the word in Aristotle's rhetoric-dialectics expounding. On the contrary, it is taken to mean no more than one thing: "counterpart". We agree with L\&Z in their criticism of too "simple" or "simplistic" an account of interdisciplinary relationships, and yet this by no means suggests justification of the preference of hard-to-read and hard-to-remember redundant terms from ancient or classical (Greek or Latin) literature of philosophy, grammar, logic, dialectics, rhetoric or linguistics, like "antistrophos". The now well-known and universally applied pragmatic principle, Grice's CP with its four maxims, does not scare readers away by any terminology hard-nuts, but makes use of easy plain language for its quadruple formulation of quantity maxim, quality maxim, relation/relevance maxim, and manner maxim. This quartet theoretical and lexical simplicity adds to the expressiveness charm of what becomes now "classical Gricean pragmatics". That is why it is the most read and quoted theory in the world of linguistics and language philosophy, and has made itself the basis for "neo-Gricean pragmatics", politeness theories, and speech act theories (or "pract theories"). On the one hand, L\&Z push "counterpart" aside in favour of "antistrophos", and on the other hand in their interpretation they cannot help utilising a series of words like or synonymous to "counterpart", e.g., "mirror-image", "proportional opposite", "exact parallel", and "equivalent". They also praise the word "antistrophos" to such an extent as being "inspiration for 'reciprocal' disciplinary reinvention" (p. 3413). However, to us, these words do not differ as much as they seem, iff (if and only if) they are contextualised in the same text, and their common semantic core is "counterpart" or "alter ego", words 
L\&Z also use in their discussions. If, as they claim, pragmatics is "antistrophos" of/to rhetoric, we do not find it inappropriate to say pragmatics is "counterpart" of/to rhetoric. What matters really is the insights in the formulation of the bilateral relationship. For any sister/sibling/twin disciplines to be called "antistrophos(es)" or "counterpart(s)" is not nonsensical, be it semantics and pragmatics, syntax and pragmatics, semantics and syntax, pragmatics and rhetoric, rhetoric and semantics, rhetoric and syntax, whatsoever pairing. Such twin-disciplinary relationship in itself suggests more or less common grounds, common academic or cultural inheritance, and common academic or cultural commitment, and in L\&Z's terms, "common interests and goals". In a nutshell, a good explanation of the relationship between pragmatics and rhetoric cannot be entrusted to the adoption of a Greek term or any other term; it depends on the author's theoretical insights for disambiguating speculations and accessible formulations. Furthermore, the meaning or significance of a term, "antistrophos" or "counterpart" in L\&Z's theorising, "implicature" for Grice's CP, "impliciture" and "explicature” in Bach’s (1999) and Sperber \& Wilson's (2001) neo-Gricean pragmatics that derive analogically from "implicature", and so on, all enjoy what can be called "author-pre-emptiveness" (Note 6), which indicates the authoritiveness of the author-he has the first say in the meaning of the term he coins, uses, or borrows. This "author-pre-emptiveness" agrees with the Saussurean "arbitrariness". Arbitrarily made, a word or term is used again and again, and by memetical conventionality, is laid down in dictionaries in due course as an acceptable or well-formed unity of form, meaning, usage and effect.

We partly agree and appreciate L\&Z's ideas about what AV is capable of, namely, helping pragmaticians and rhetoricians understand the meaning of such important keywords as "intention", "meaning", and "effect" so they can use these terms properly, and ultimately coordinate the two disciplines in isolation or in collaboration, and boost the independent or "mutual transformation" by drawing "inspiration" from one another. The problem with them perhaps lies in this "transformation" capability standing against L\&Z's anti-mutual-appropriation view.

Also, about the pragmatics-rhetoric relationship, we disagree with Hopper's (2007) "synecdochic perception" view, holding rhetoric as nothing but "a form of pragmatics" and holding pragmatics and other non-rhetoric disciplines as nothing but a "micro end of rhetoric" (L\&Z, 2011, p. 236). We also disagree with Dasenbrock's (1987) "Austinian rhetoric" and Dascal and Gross's (1999) "Gricean/cognitive rhetoric", both narrow-minded, where we see one discipline "eating up" another. L\&Z reasonably point out that we should try to knock down the "walls" of interdisciplinary tensions and contradictions, and build up pragmatics and rhetoric as mature "independent disciplines" by common academic interest, orienting towards a new and reasonable interdisciplinary relationship network, where emerges very frequently what Burke (1945/1969. p. 403) calls "competition of cooperation" or "cooperation of competition". Such being the case, this academic vista should owe more to L\&Z's AV than to their term "antistrophos" and NCP (see Hou, forthcoming, b)). 


\section{Integration of "Antistrophos Disciplines"}

Nowadays we can see pragmatic studies of rhetoric and rhetorical studies of pragmatics going on side by side, namely, the two disciplines snowballing with great rapidity by mutual lend-lease (see Jiang, 2009, p. 76). As we can see, most if not all pragmatic principles apply to a great extent to rhetoric and its research. Actually pragmatics used to facilitate the birth and early development of rhetoric and now is boosting the modern development of rhetoric, leading rhetoric up a new paradigm of dynamic interdisciplinary rhetorical studies (Wang \& Chen, 2005, p. 532). Such interdisciplinary rhetorical approaches are widely adopted by Li (2005, 2008), Xu (2007), Jiang (2008a, 2008b, 2009), Chen (2009, 2010), Hou (2011, 2012a, 2012b), Jiang (2013, 2014), Wu and Hou (2015), to name but a few. Such studies can also be found in more than forty recent papers published in Contemporary Rhetoric, the only rhetoric journal in China.

Hou (forthcoming a)), in his discussion about the possibility of fusing pragmatics and rhetoric, hackles the twenty "predicaments" of the two disciplines, ten for each. It is argued that the commonness can justify the pragmatics-rhetoric integration, paving the way for pragma-rhetoric as a new interdiscipline. The differences between the two subjects, on the other hand, can account for the necessity and possibility of the relevant mutual complementarity. The past literature of pragmatics and rhetoric suggests a general misunderstanding about "integration". It is also argued that "pract" (pragmatic/speech act) and "rhetorical act" enjoy a great deal of resemblance to each other, so that the two terms from the two disciplines can be integrated into one term: "Pragma-Rhetorical Act" (PRA). Hou (ibid.) formulates the goals for the new interface study of "pragma-rhetoric" to find out a) about the mechanism of PRA, b) about how exactly all the contextemes (contextual factors and cues) work in actual pragma-rhetorical communications of various forms, c) about all the pragma-rhetorical means, strategies, structures, and functions, d) about all pragma-rhetorical rules and principles that govern daily written and oral communications, verbal or non-verbal. It is seen that pragma-rhetoric is a new interdisciplinary (social) science in art and art in science, subsumed below linguistics and naturally below language philosophy. Due to various research paradigms, pragma-rhetoric can be pragmatic studies of rhetorical matters, rhetorical studies of pragmatic issues, or studies of language problems and strategies from the joint, syncretic perspective of pragma-rhetoric (more of pragmatics or rhetoric, as cases vary, as authors vary).

Finally, as pragmatics and rhetoric are "sized up" (Note 7) as "antistrophos disciplines", as L\&Z claim, the pragmatics-rhetoric integration or its consequent interface study "pragma-rhetoric" had better not be described as a "marriage" to avoid academic "endogamy" or "close breeding".

\section{Conclusion}

It is common knowledge now that pragmatics is particularly keen on the rules or principles governing language use and usages, and appropriateness and strategicality, while rhetoric focuses on the rhetoricality, euphoniousness, and effectiveness (Hou, 2014, p. 185). Pragmatic and rhetoric research in 
recent years has seen hand-in-hand cooperation here and there, leading to the origination of a new paradigm of pragma-rhetoric (Jiang, 2009, p. 76). As the two disciplines are prominent linguistic disciplines nowadays, their integration is creating a win-win prospect of development.

We benefit a good deal from Liu \& Zhu's paper though there are a few points in their formulation that engender our curious suspicion. This current study is only an introduction to and random comment on L\&Z's "antistrophos view of pragmatics-rhetoric relationship", or AV. We represent their ideas about why they prefer "antistrophos" to "counterpart" for the bilateral relationship. We hold that most of their theoretical formulation is meaningful and helpful to the two disciplines and their interdisciplinary approaches. However, we maintain that "counterpart" can be as good as or better than "antistrophos", which means no more than the significance of "counterpart". We suspect that it is only their lexical/terminological game. Despite this terminology disagreement, we believe in most of their AV points, capable of coordinating "reciprocal and reversible transformation(s)" (L\&Z, p. 3414) of the two disciplines and facilitating "mutual appropriation". Moreover, by means of some methods and notions from traditional tripartite comparisons of pragmatics, semantics and syntax, we expound the pragmatics-rhetoric relationship. We maintain the view of "radical pragmaticism of complementarism", believing that this stance can promote the win-win cooperation between them to reach for a better, elevated interdisciplinary horizon (see L\&Z, ibid.) and a promising vista of pragmatic and rhetorical development and their twin-integration.

\section{Acknowledgements}

We are immensely grateful to the National Scientific Research Programme of China (A Metaphorical ERP-based Study of Chinese and English Tropes: 15XY001), and Innovative Pragma-Rhetoric Team Programme of Huaqiao University for funding, and to Yong Yang, Chunrong Wu, Qiuhong Xing, Jingjing Chen, Jing Qian, Feifeng Sun, Zhijun Li, Qingsheng Jiang, Fenglin Wu, and Trevor Decian for proofreading and advice.

\section{References}

Abbott, P. (2006). Splendor and misery: Semiotics and the end of rhetoric. Rhetorica: A Journal of the History of Rhetoric, 24(3), 303-323. https://doi.org/10.1525/rh.2006.24.3.303

Aristotle. (1991/2007/2010). On Rhetoric (A. K. George, Trans.). NY: OUP.

Bach, K. (1999). The myth of conventional implicature. Linguistics and Philosophy, 22, 262-283. https://doi.org/10.1023/A:1005466020243

Beale, W. (1978). Rhetorical performative discourse: A new theory of epideictic. Philosophy and Rhetoric, 11(4), 221-246.

Benjamin, J. (1976). Performatives as a rhetorical construct. Philosophy and Rhetoric, 9(2), 84-95.

Bohman, J. (1988). Emancipation and rhetoric: The perlocutions and illocutions of the social critic. Philosophy and Rhetoric, 21(3), 185-204. 
Brown, K. et al. (Eds.). (2008). Encyclopedia of Language \& Linguistics (Vol. 10). Shanghai: Shanghai Foreign Language Education Press.

Burke, K. (1945/1969). A Grammar of Motives. Berkeley: University of California Press.

Burke, K. (1950/1969). A Rhetoric of Motives. Berkeley: University of California Press.

Cassin, B., \& Goffey, A. (2009). Sophistics, rhetorics, and performance; or, how to really do things with words. Philosophy and Rhetoric, 42(4), 349-372. https://doi.org/10.1353/par.0.0044

Chen, C. (1985). Pragmatics and rhetoric. Yangzhou Normal University Journal (Social Science), 2, 33-36.

Chen, R. D. (2010). Modern Chinese Rhetoric. Beijing: Peking University Press.

Chen, R. D. (Ed.). (2009). Symposium of Rhetorical Studies. Harbin: Heilongjiang People's Press.

Chen, W. D. (1932/2008). Basics of Rhetoric. Shanghai: Dajiang Shupu \& Fudan University Press.

Chi, C. H. (1989). Rhetoric and pragmatics: A discussion with Yulin Yuan. Rhetoric Studies, 1, 38-39.

Dascal, M., \& Gross, A. G. (1999). The marriage of pragmatics and rhetoric. Philosophy and Rhetoric, 32(2), 107-130. https://doi.org/10.1353/par.1999.0001

Dasenbrock, R. W. (1987). J. L. Austin and the articulation of a new rhetoric. College Composition and Communication, 38(3), 291-305. https://doi.org/10.2307/357749

Grice, H. P. (1989). Studies in the Way of Words. Cambridge, Mass.: HUP.

Gu, Y. G. (1993). The impass of perlocution. Journal of Pragmatics, 20, 405-432. https://doi.org/10.1016/0378-2166(93)90038-Q

Gu, Y. G. (1994). Pragmatics and rhetoric: A collaborative approach to conversation. In H. Parret (Ed.), Pretending to Communicate (pp. 173-195). Berlin: Walter de Gruyter.

He, Z. R. (2000). What rhetoric can learn from pragmatics. Jinan Journal (Social Science), 6, 38-44.

He, Z. R., \& Chen, X. R. (2004). English Grammar in Use. Beijing: Foreign Language Teaching and Research Press.

Hopper, P. (2007). Linguistics and micro-rhetoric: A twenty-first century encounter. Journal of English Linguistics, 35(3), 236-252. https://doi.org/10.1177/0075424207305307

Horn, L. (1984). Towards a new taxonomy for pragmatic inference: Q-based and R-based implicature. In D. Schiffrin (Ed.), Meaning, Form and Use in Context (GURT '84) (pp. 11-42). Washington: Georgetown University Press.

Horn, L. (2004). Implicature. In L. Horn, \& G. Ward (Eds.), The Handbook of Pragmatics (pp. 3-28). Oxford: Blackwell Publishing.

Hou, G. J. (2011). A pragma-rhetorical approach to syllepsis and its translation. Foreign Language Researching, 6, 109-114.

Hou, G. J. (2012a). A pragma-rhetorical approach to zeugma and its translation. Foreign Languages and Their Teaching, 3, 29-32.

Hou, G. J. (2012b). Is Tom Swifty English-specific?-Possibility of generating TS in Chinese. Contemporary Rhetoric, 5, 70-80. 
Hou, G. J. (2013). Semantics and pragmatics: Which dominates which?-Discussion of complementarism and the interdisciplinary trend of pragmatics. Foreign Language Research, 2, 24-35.

Hou, G. J. (2014). Essence of Pragmatics: Pragmatic Competence vs. Pragmatic Failure. Beijing: China Publishers Group.

Hou, G. J. (in press a)). Is pragma-rhetoric possible? Manuscript submitted for publication.

Hou, G. J. (in press b)). My views on Non-Cooperative Principle of Liu \& Zhu. Manuscript submitted for publication.

Hu, F. Z. (2003). From rhetorical skills to speech acts: The pragmatic turn of rhetorical studies in China. Rhetoric Studies, 1, 2-5.

Huang, Y. (1994). The Syntax and Pragmatics of Anaphora: A Study with Special Reference to Chinese. Cambridge: CUP.

Huang, Y. (2001). Reflections on theoretical pragmatics. Journal of Foreign Languages, 1, 2-14.

Ilie, C. (2001). Book review of Jef Verschueren, understanding pragmatics. Journal of Pragmatics, 33, 323-331. https://doi.org/10.1016/S0378-2166(00)00022-9

Ilie, C. (2003). Pragma-rhetoric-Approaches to rhetoric pragmatics interface. Retrieved from http://www/oru.se/oru-upload/Institutioner/Humaniora/Dokument

Jarratt, S. (2007). Rhetoric. In D. G. Nicholls (Ed.), Introduction to Scholarship in Modern Languages and Literatures (pp. 73-102). NY: Modern Language Association of America.

Jiang, Q. S. (2013). A pragma-rhetorical investigation of the Chinese jishou. Studies in Linguistics and Literature, 2, 39-52.

Jiang, Q. S. (2014). The Pragmatic conditions and planning of idiom parody. Foreign Language Education, 2, 31-34.

Jiang, Y. (2008a). A cognitive-rhetorical approach to relevance theory. Rhetoric Studies, 3, 1-9.

Jiang, Y. (2008b). A cognitive-rhetorical approach to relevance theory. Rhetoric Studies, 4, 14-21.

Jiang, Y. (2009). Relevance theory and Chinese rhetoric studies. In R. D. Chen (Ed.), Symposium of Rhetorical Studies (pp. 76-84). Harbin: Heilongjiang People's Press.

Jost, W., \& Olmsted, W. (Eds.). (2004). A Companion to Rhetoric and Rhetorical Criticism. Oxford: Blackwell Publishing.

Larsson, S. (1998). Ancient rhetoric and modern pragmatics. Course paper in the history of linguistics, autumn of 1998. Retrieved from http://www.ling.gu.se/ sl/papers.html and http://www.citeseerx.ist.psu.edu/viewdoc/summary?doi=10.1.1.126.8994

Leech, G. (1983). Principles of Pragmatics. London: Longman.

Leith, D. (1994). Linguistics: A Rhetor's guide. Rhetorica: A Journal of the History of Rhetoric, 12(2), 211-226. https://doi.org/10.1525/rh.1994.12.2.211

Levinson, S. (2001). Pragmatics. Beijing: Foreign Language Teaching and Research Press.

Li, J. (2005). Pragma-rhetorical Surveys. Canton: Canon Education Press.

Published by SCHOLINK INC. 
Li, J. (2008). Discourse Rhetoric: Theories and Practice. Shanghai: Shanghai Foreign Language Education Press.

Li, Y. H. (2002). The background of the possible foundation for Chinese pragmatic rhetoric. Zhejiang Normal University Journal (Social Science), 2, 94-97.

Liu, D. W. (2003). Speechology, rhetoric or pragmatics? Rhetoric Studies, 3, 1-5.

Liu, Y. M. (2004). Relevance and rhetoric. Foreign Language Teaching and Research, 4, 252-256.

Liu, Y. M., \& Zhu, C. S. (2011). Rhetoric as the Antistrophos of pragmatics: Toward a "Competition of Cooperation" in the study of language use. Journal of Pragmatics, 43, 3403-3415. https://doi.org/10.1016/j.pragma.2011.07.010

Lunsford, A. A. et al. (2009). Introduction: Rhetorics and roadmaps. In A. A. Lunsford et al. (Eds.), The Sage Handbook of Rhetorical Studies (pp. xi-xxix). Thousand Oaks: Sage Publications.

Lyons, J. (2000). Linguistic Semantics: An Introduction. Beijing: Foreign Language Teaching and Research Press.

Qi, Y. C. (1983). Rhetoric and pragmatics. In Fudan University Language Lab. (Ed.), Wangdao Chen's "Basics of Rhetoric" and Chinese Rhetoric (pp. 377-384). Shanghai: Fudan University Press.

Qi, Y. C. (1986). Rhetoric-pragmatic relation revisited. Rhetoric Studies, 1, 5-7.

Richards, J. (2008). Rhetoric. London: Routledge.

Saeed, J. (2012). Semantics. Beijing: Foreign Language Teaching and Research Press.

Sperber, D, \& Wilson, D. (2001). Relevance: Communication and Cognition. Beijing: Foreign Language Teaching and Research Press.

Sperber, D., \& Wilson, D. (1990). Rhetoric and relevance. In J. Bender, \& D. Wellbery (Eds.), The Ends of Rhetoric: History, Theory, Practice (pp. 140-156). Stanford: Stanford University Press.

Verschueren, J. (1995). The pragmatic perspective. In J. Verschueren et al. (Eds.), Handbook of Pragmatics: Manual (pp. 1-19). Amsterdam: John Benjamins Publishing Company.

Verschueren, J. (2000). Understanding Pragmatics. Beijing: Foreign Language Teaching and Research Press.

Wang, D. C., \& Chen, C. (2005). Modern Rhetoric. Shanghai: Shanghai Foreign Language Education Press.

Wilson, D., \& Sperber, D. (2004). Rhetoric and relevance. In L. Horn, \& G. Ward (Eds.), The Handbook of Pragmatics (pp. 607-632). Oxford: Blackwell Publishing.

Wu, C. R., \& Hou, G. J. (2015). A pragma-rhetorical interpretation of parody advertisements and principle of parody translation. Contemporary Rhetoric, 1, 70-77.

Xu, P. (2007). Rhetoric and Pragmatics: A Comparative Study of Chinese Rhetorical Devices. Shanghai: Shanghai Foreign Language Education Press.

Yuan, Y. L. (1987). Pragmatics and rhetoric: Theoretical goals tasks and perspectives. Qiqihaer Normal University Journal (Social Science), 2, 41-46.

Zarefsky, D., \& Benacka, E. (Eds.). (2007). Sizing up Rhetoric. Long Grove: Waveland Press.

Published by SCHOLINK INC. 
Zhang, H. S. (2000). On rhetoric and pragmatics. Rhetoric Studies, 4, 24-25.

Zhang, Y. Q. (2015). Revisiting pragmatics and rhetoric from the perspective of NCP. Journal of Zhejiang International Studies University, 3, 2-7, 27.

Zong, S. H., \& Liu, W. H. (2007). On rhetoric-pragmatics relationship and their development orientation. Jinan Journal (Social Science), 5, 119-126.

\section{Notes}

Note 1. For discussion and remedy of their NCP, see Hou (in press b)).

Note 2. Aristotle (Rhetoric, p. 1354), qtd from L\&Z (p. 3412).

Note 3. Also see L\&Z (p. 3213). Retrieved from https://www.coursehero.com/file/6158519/Burke-part-2 and http://www.azquotes.com/quote/713219

Note 4. In imitation of the Kantian apophthegm: "Concepts without percepts are empty; percepts without concepts are blind" (from Critique of Pure Reason), Huang (2001, p. 9) says, "[P]ragmatics without syntax is empty; syntax without pragmatics is blind". I think that here the non-pragmatics discipline (syntax) is mentioned metonymically, for it can be any other basic or important linguistic inquiry like semantics, lexicology, rhetoric, construction grammar, and stylistics.

Note 5. Written by 刘妿/Liu Xie (surname being “Liu”) in the Nansong Dynasty (960-1279 AD), the book is a literary work of 10 volumes or 50 sections, based on Confucianism and Taoism. Liu represents the acme of ancient Chinese aesthetics.

Note 6. My imitation of Levinson's (2001, p. 64) "deictic pre-emptiveness", referring to the preferential use of a shorter, easier, or more general deictic term, like "tomorrow", rather than its longer, harder, or specific deixis like "July 20, 2017" or "this Thursday", if this "tomorrow" happens to be this date.

Note 7. Expression of Zarefsky and Benacka (2007). 